\title{
A comparative study between coblation and bipolar electrocautery tonsillectomy in children
}

\begin{abstract}
Hemin I brahim Saeed* Abdulkhaliq Emin** Moyaser A. Yaseen** Ammar M. Saleh*
Abstract

Background and objective: Tonsillectomy with or without adenoidectomy is an operation done frequently in all otolaryngology departments all over the world. Many new surgical techniques found over the last few decades to decrease the morbidity of this surgery. This study aimed to compare intraoperative efficiency and postoperative recovery between coblation and bipolar electrocautery tonsillectomy.

Methods: This prospective study was carried out on 60 patients that underwent tonsillectomy over six months from 1(st) August 2014 to 31(st) January 2015 in Rizgary Teaching Hospital, Erbil city. They patients equally divided into two groups; coblation tonsillectomy (30 patients) and bipolar electrocautery tonsillectomy (30 patients). Their age ranged between 2.5-12 years. The operative time and intraoperative blood loss were recorded for each patient and compared. The parents were given a pain diary to record the level of pain each morning for ten days. Also, they were asked to report any complication like bleeding.

Results: There was no statistically significant difference in the mean operation time between the coblation group and bipolar electrocautery group (6.89 min vs. $7.83 \mathrm{~min}$, $P=0.11)$. The mean intraoperative blood loss was statistically lower for the bipolar electrocautery group versus the coblation group $(1.43 \mathrm{ml}$ vs. $15.37 \mathrm{ml}, P<0.001)$. There was a statistically significant difference in the daily pain scores between the two groups in which the coblation group was associated with lower mean pain score. No episodes of primary or secondary hemorrhage were recorded.
\end{abstract}

Conclusion: Bipolar electrocautery tonsillectomy offers the same operative speed, less intraoperative blood loss, more postoperative pain scores when compared with coblation tonsillectomy.

Keywords: Tonsillectomy; Coblation tonsillectomy; Bipolar electrocautery tonsillectomy.

\section{Introduction}

Tonsillectomy is one of the most common surgical procedures performed in the ear, nose, and throat (ENT) practice. ${ }^{1}$ Over the last few years, different techniques for performing tonsillectomy have been proposed as attempts to lower the inherent morbidity of this surgery. ${ }^{2}$ These techniques include blunt cold steel dissection, guillotine excision, monopolar diathermy, bipolar diathermy, laser dissection, bipolar scissor dissection and recently coblation tonsillectomy. ${ }^{3}$ Any new tonsillectomy procedure needs to be comparable, or even better than present technique in terms of morbidity, mortality, safety of use, short learning curve, and cost-effectiveness. It should also be associated with less postoperative pain and intraoperative blood loss, and result in a more rapid return to normal diet and activity and carry a lower risk of both reactive and secondary hemorrhage. ${ }^{4}$ There is still controversy over which is the optimal technique of tonsillectomy with the lowest morbidity rates. $^{5}$ In contrast to the majority of operative procedures associated with primary wound closure,

* Department of Otolaryngology, Rizgari Teaching Hospital, Erbil, I raq.

** Department of Otolaryngology, College of Medicine, Hawler Medical University, Erbil, I raq. 
tonsillectomy leaves an open wound that undergoes healing by second intention, thus opening the possibility of postoperative complication. ${ }^{6}$ Coblation is a bipolar system that involves passing radiofrequency through a medium of normal saline, which results in the production of a plasma field of sodium ions, these ions can break down intercellular bonds and in effect vaporize tissue at a temperature of only $60^{\circ}-80^{\circ} \mathrm{C}$. The presence of irrigating saline helps limit the amount of heat delivered to the surrounding tissues. ${ }^{7}$ Coblation surgery as one of the different types of radiofrequency surgery is a novel surgical technique that was first introduced in ENT practice in late 1990 for the operation of the head and neck soft tissues. ${ }^{8}$ However, there is a significant cost implication to use coblator device. ${ }^{9}$ In bipolar electrocautery tonsillectomy, an electric current passed through the tissue between two electrodes (blades), cuts the tissue and simultaneously seals the blood vessels. This approach is associated with more postoperative pain attributed to the spread of thermal injury due to the high temperatures used. ${ }^{10}$ In bipolar electrocautery, direct contact between electrodes and tissue produces local temperatures of $400 \mathrm{C}-600 \mathrm{C}$ resulting in heating of intracellular content and subsequent vaporization of the cells. ${ }^{11,12}$ This technique was introduced 40 years ago and commonly used. ${ }^{13}$ Electrocautery tonsillectomy typically affords greater operative speed and less operative blood loss. ${ }^{14}$ Edema and pain are greatest immediately after surgery, probably as a result of thermal effects and expression of inflammatory mediators that stimulate pharyngeal nociceptors. After tonsillectomy within few hours a fibrin clot formed, epithelial ingrowth beneath a fibrin clot begins shortly after wounding. Separation of the fibrin clot about seven days after surgery exposes vascular stroma. Involution of the vascular stroma and completion of epithelial coverage (wound healing) may take about two weeks, and during this period bleeding can occur. ${ }^{15}$ This study aimed to compare the results of tonsillectomy by coblation with that done by the bipolar electrocautery method in several points.

\section{Methods}

A prospective comparative study conducted on 60 patients. They were divided into two groups, first group (group A) tonsillectomy done by coblation which include 30 patients and second group (group B) tonsillectomy done by bipolar electrocautery which include 30 patients, the period was six months from $1^{\text {st }}$ August 2014 to $31^{\text {st }}$ January 2015 in the ENT Department of Rizgary Teaching Hospital, Erbil city. Before commencement, the study protocol was approved by the College of Medicine ethics committee, Hawler Medical University. Inclusion criteria include patients 12 years and younger with indications of tonsillectomy. Exclusion criteria include patients with a history of bleeding disorders, peritonsillar abscess, any significant chronic illness that would interfere with expected recovery, history of tonsillitis within three weeks prior to surgery, and medically unfit. Following history taking a routine clinical assessment and examination was done. Then the patients investigated by complete blood count, blood group and Rh, bleeding time, clotting time and virology screen. All tonsillectomy techniques were done under general anesthesia, and general anesthetic technique was standardized for all patients. The surgical dissection technique was the same for both coblation and bipolar electrocautery tonsillectomy, and involved a subcapsular dissection of tonsil for complete excision of the tonsil, with the effort made to preserve as much pharyngeal mucosa as possible. The collection group of patients had tonsillectomy performed using the ArthroCare ENT Coblator II surgery system with EVac 70 plasma wands (ArthroCare Corp., Sunnyvale, CA, USA). The wand 
is composed of five active electrodes that are placed at the distal end of the tip. The exposed portion of the shaft acts as the return electrode just proximal to the active electrodes. The settings were standardized at seven for coblation and three for coagulation. Bipolar electrocautery group of patients had tonsillectomy using a bipolar machine which set at 20 -25 watt for coagulation, using bipolar forceps in which the current passes between the two tips of the forceps, an upper pole incision was made with cautery, the capsule of palatine tonsil was identified and dissected from superior to inferior pole with careful cauterization of the tissue. Bleeding points usually very few following excision of the tonsil were selectively secured with bipolar diathermy. No snare was used, and further hemostasis was secured by point coagulation, no ligatures were used. Each tonsillectomy technique was intra-operatively assessed for operative time by calculating the time from the first incision to complete hemostasis of the tonsillar bed. The intraoperative blood loss was recorded by measuring the blood collected in the suction bottle after subtracting the volume of saline used for coblation method and it was care was taken not to use swabs as much as possible. Postoperatively, the patients remained in the hospital and were observed for 6 hours then discharged after being given similar prescriptions of antibiotics (oral amoxicillin + clavulanic acid 312 (250/62) $\mathrm{mg} / 5 \mathrm{ml}$. suspension in a dose of $0.15 \mathrm{ml} / \mathrm{kg} /$, every 8 hours for seven days) and analgesic medication (acetaminophen 10-15 mg/kg/dose orally every 6 hour). Patients with hypersensitivity to penicillin had been given oral erythromycin $30-50 \mathrm{mg} / \mathrm{kg} /$ day in four divided doses. Patients were given verbal as well as written instructions regarding medication at home along with guidance regarding food intake and general care. All study participants were asked to fill out a daily pain diary for ten consecutive days postoperatively. The daily diary included a commonly used standardized pain scale (Wong-Baker FACES pain rating scale) which is a $0-10$ numerical rating scale with correlating faces (from happy to sad) to allow children to record their pain. Parents provided information for those children too young to comply. The parents were given a copy of the pain scale (Wong-Baker FACES pain rating scale). The instruction was given to the parents about filling the pain chart. All patients were followed up for ten days by daily contacting their parents by telephone. The degree of pain of the throat marked on a scale first thing each morning, before taking any analgesic medication. Patients were all seen in the outpatient department on the $10^{\text {th }}$ and $14^{\text {th }}$ postoperative days and their throat was examined with a subjective measure about the area of the tonsillar fossa that was healed or covered in the slough, and the questionnaire was completed. Data analysis was carried out using the statistical package for the social science (version 19). Chi-square test was used to compare between proportions. Student's t-test was used to compare between two means. A $P$ value of equal or less than 0.05 was considered statistically significant. Fisher's exact test is used When the expected count of more than $20 \%$ of the cells of the row*column table was less than 5 .

\section{Results}

A total of 60 patients were recruited into this prospective study. Their age ranged from 2.5-12 years, sex distribution was 33 (55\%) males and 27 (45\%) females.

Duration of operation: The duration of operation was found to be statistically not significant between the two groups, in which the mean operative time in Group A was 6.89 minutes (range 3-12 minutes), while the mean operative time in Group B was 7.83 minutes (range $2.5-12$ minutes), $P=0.11$ as shown in Figure 1.

Intraoperative blood loss: Intraoperative blood loss was found to be statistically highly significant between the two groups, 
https:/ / doi.org/ 10.15218/ zjms.2019.011

in which mean blood loss in Group A was $15.37 \mathrm{ml}$ which ranged from $(5-25) \mathrm{ml}$, while mean blood loss in Group B was 1.43 $\mathrm{ml}$ which ranged from $(1-4) \mathrm{ml}(P<0.001)$ as shown in Figure 2.

Postoperative pain: Mean pain score was computed for each patient over ten days and summary statistics were obtained for the two groups as shown in Figure 3. A significant difference in pain score was revealed between coblation method and bipolar electrocautery method in which the Group A (coblation group) was associated with lower mean pain score than Group B (bipolar electrocautery group).

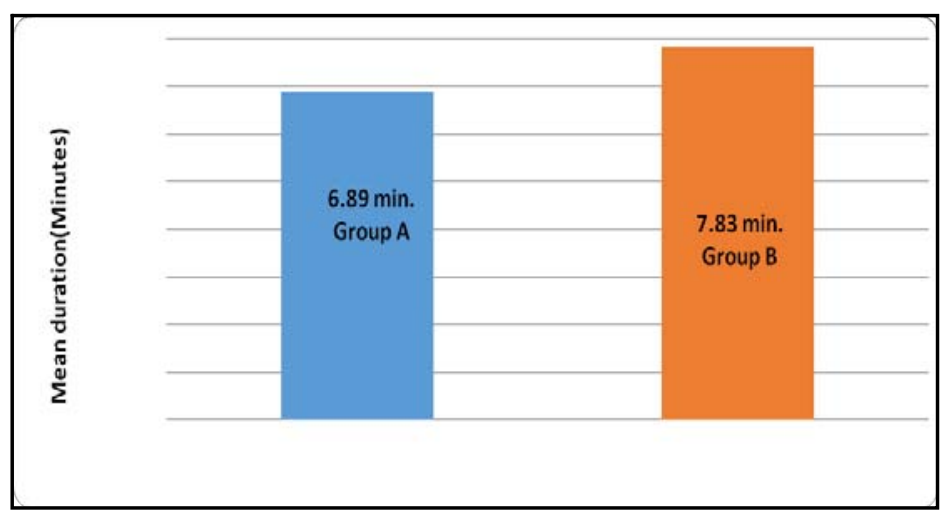

Figure 1: Mean duration of operation in minutes between the two groups.

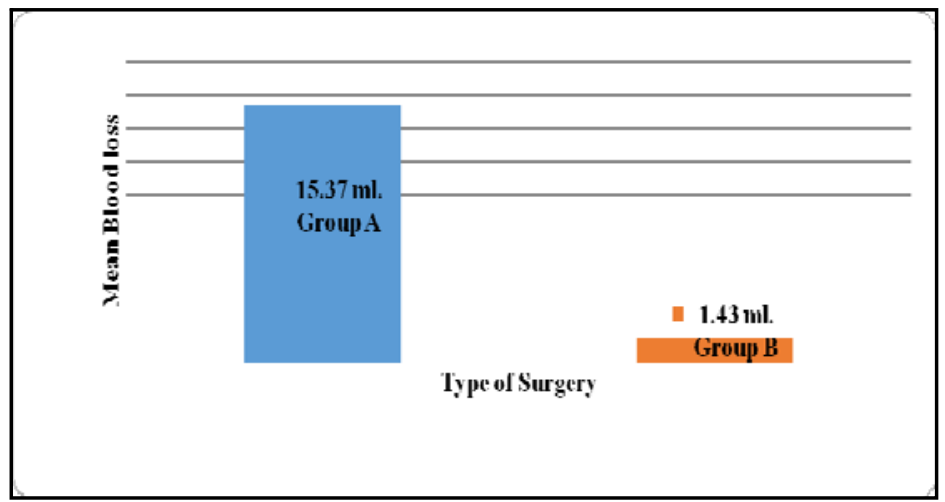

Figure 2: Mean intraoperative blood loss in $\mathrm{ml}$ between two groups.

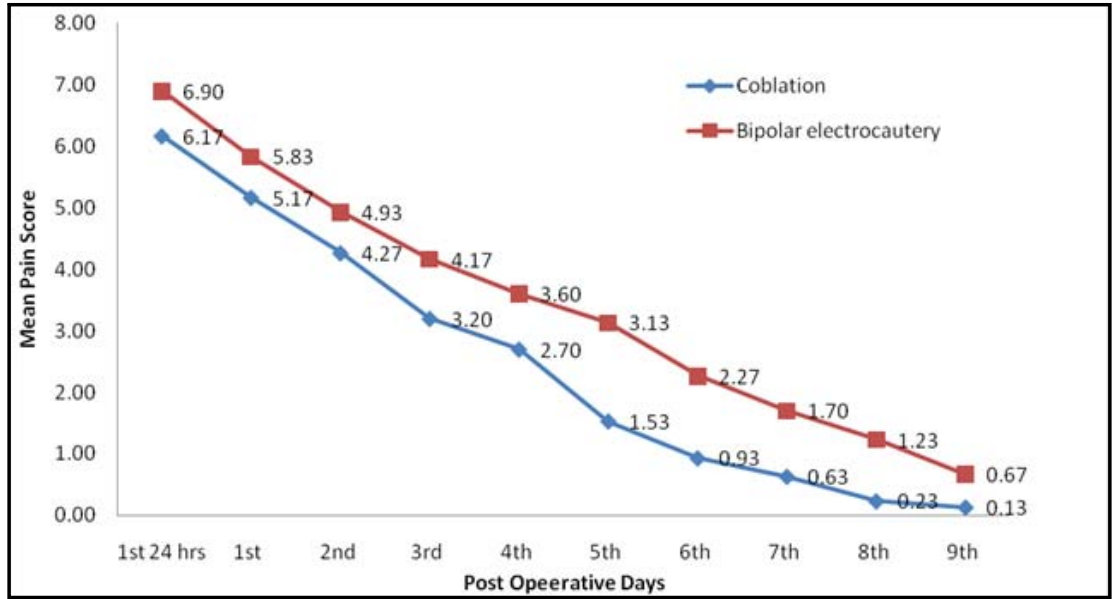

Figure 3: Mean pain score for both coblation and bipolar electrocautery tonsillectomy. 
Hemorrhage: There were no episodes of primary and secondary bleeding.

Healing: The throat was examined at $10^{\text {th }}$ postoperative day (POD). In Group A (coblation group), the appearance of tonsillar fossa was healed in 14 patients and was not healed in16 patients, i.e., slough was present in tonsillar fossa. In Group B (bipolar electrocautery group), the appearance of tonsillar fossa was healed in only eight patients and was not healed in 22 patients. This difference was statistically not significant $(P=0.18)$ as shown in Table 1. At $14^{\text {th }}$ postoperative day (POD), Group A showed that 26 patients were healed, and four patients were not healed (slough was present in tonsillar fossa). In Group B, 18 patients were healed, and 12 patients were not healed (slough was present in tonsillar fossa). This difference was statistically significant $(P=0.039)$ as shown in Table 2.

Table 1: Throat examination in two groups on $10^{\text {th }}$ POD.

\section{Appearance of tonsillar fossa at $10^{\text {th }}$ \\ POD}

\begin{tabular}{lccccccc} 
Operation type & \multicolumn{2}{c}{ Healed } & \multicolumn{2}{c}{ Non healed } & \multicolumn{2}{c}{ Total } & $P$ value \\
& No. & $\%$ & No. & $\%$ & No. & $\%$ & \\
\hline Group A & 14 & 46.7 & 16 & 53.3 & 30 & 100 & \\
Group B & 8 & 26.7 & 22 & 73.3 & 30 & 100 & 0.18 \\
Total & 22 & 36.7 & 38 & 63.3 & 60 & 100 & \\
\hline
\end{tabular}

Table 2: throat examination in two groups on $14^{\text {th }}$ POD.

\section{Appearance of tonsillar fossa at}

$14^{\text {th }}$ POD

Operation type

Healed Non healed Total $P$ value

\begin{tabular}{lccccccc} 
& No. & $\%$ & No. & $\%$ & No. & $\%$ & \\
\hline Group A & 26 & 86.6 & 4 & 13.4 & 30 & 100 & \\
Group B & 18 & 60.0 & 12 & 40.0 & 30 & 100 & 0.039 \\
Total & 44 & 73.3 & 16 & 26.7 & 60 & 100 & \\
\hline
\end{tabular}




\section{Discussion}

No study has been done previously, comparing coblation and bipolar electrocautery tonsillectomy in children. In this study, mean operative time in group A (coblation group) was 6.89 min., while mean operative time in group $\mathrm{B}$ (bipolar electrocautery group) was 7.83 min., and this result statistically not significant $(P=0.11)$. Also mean intraoperative blood loss in group A was $15.37 \mathrm{ml}$, while mean intraoperative blood loss in group B was $1.43 \mathrm{ml}$ which were statistically highly significant $(P<0.001)$. In a study which conducted by Parson et al. in 2006, which made a 3-way comparison including coblation, monopolar electrocautery, and ultrasonic scalpel tonsillectomies, showed that electrocautery tonsillectomy has advantages of lesser intraoperative blood loss and greater operative speed when compared with coblation tonsillectomy. ${ }^{16}$ Regarding duration of operation, which was different from our study, in which operative time was higher in the combination group than electrocautery group, and this might be due to that the sample size was larger than our sample size, as he conducted his study on 134 patients. While the result of intraoperative blood loss looks similar to the result of our study, in which in both study electrocautery had the advantage of lesser intraoperative blood loss than coblation. Another study conducted by Magdy et al. in 2008, which compared coblation tonsillectomy with dissectionligation, monopolar electrocautery and laser tonsillectomies in the same patient, showed that mean operative time in the coblation side was $12 \mathrm{~min}$. and in electrocautery, the side was $10 \mathrm{~min}$. $(P=0.981)$. Also, mean intraoperative blood loss between coblation and electrocautery sides were $5 \mathrm{ml}$ and $12.5 \mathrm{ml}$ respectively $(P=0.214) .{ }^{17}$ Regarding intraoperative blood loss which differed from our study, this might be due to that Magdy conducted his study using monopolar electrocautery, not bipolar electrocautery, and his patients were adults. Chang KW. In 2005 did a study on 101 patients, (collation versus monopolar electrocautery tonsillectomy), age ranged from (2-16) years, which showed that mean operative time was similar between 2 groups, and this result was similar to the result of our study. While mean estimated blood loss in the coblation group was $16.2 \mathrm{ml}$. and in the electrocautery group was $26.8 \mathrm{ml}$. Although there was a tendency in the electrocautery group for slightly greater bleeding, this was not statistically significant $(P=0.17){ }^{18}$ Regarding intraoperative blood loss that differed from our study and this might be due to the sample size that was larger than our sample size, and he used monopolar electrocautery. Another study which conducted by Fawzy et al. in 2012, (one tonsil removed by coblation and the other tonsil removed by bipolar diathermy) and showed that operative time and operative blood loss were significantly less in the collection sides $(P<0.001)$, in which mean operative time and operative blood loss in coblation sides were $7.97 \mathrm{~min}$. and $29.77 \mathrm{ml}$ respectively, while in electrocautery sides were $11.67 \mathrm{~min}$. and $44.23 \mathrm{ml}^{19}$ Regarding operative time and intraoperative blood loss were significantly less in coblation sides, which was differ from the current study and this might be due to that the sample size of the study which conducted by Fawzy was small (30 patients), and he conducted his study on adult patients. Regarding postoperative pain, in our study the mean pain score was computed for each patient over ten days, the result of our study was that group A (coblation group) had lower mean pain score when compared with group B (bipolar electrocautery group). This result supported by a study which conducted by Fawzy et al. in 2012, (one tonsil removed by coblation and the other tonsil removed by bipolar diathermy) which showed that mean pain score in coblation sides was significantly lower compared to electrocautery sides especially in the first and second postoperative days. ${ }^{19}$ 
Parson et al. made a 3-way comparison including coblation, monopolar electrocautery, and ultrasonic scalpel tonsillectomies, and found that coblation tonsillectomy was associated with lowest mean pain level. ${ }^{16}$ Again the result of this study was similar to the result of our study. Magdy et al. in 2008 did a study, which compared coblation tonsillectomy with dissection-ligation, monopolar electrocautery and laser tonsillectomies in the same patient, which showed that coblation sides had consistently highly significant lower mean pain scores compared with electrocautery sides. ${ }^{17}$ The result of this study was similar to the result of our study. Chang in 2005 did a study (collation versus monopolar electrocautery tonsillectomy) in children (2-16) years, found a marked difference in postoperative pain score and return to normal diet in favor of coblation. ${ }^{18}$ The result of this study was similar to the result of our study. On the other hand, a study which conducted by Tan et al. in 2006, compared coblation and monopolar electrocautery tonsillectomy in adults showed that there were no significant differences in the daily visual analog score for pain between coblation and electrocautery tonsillectomy. ${ }^{20}$ Also, Pham et al. in 2014 in his study (postoperative outcomes in combination versus electrocautery tonsillectomies) found that there was no statistically significant difference in the mean pain score between the two groups. ${ }^{21}$ Stoker et al. did a study in 2004 on pediatric total tonsillectomy using coblation compared to conventional electrocautery. They similarly found that there was no difference in post-operative return to diet, normal activity and absence of pain between the two techniques. ${ }^{22}$ Pain is a very difficult response to study, as it is a very subjective symptom with significant interpatient variability. Pain will probably vary from a person to another even if all other factors stay constant. Thus, a fixed amount of pain generated by a single procedure may be relatively mild for an individual with a high threshold of pain. However, it may be perceived as severe pain for another individual who has a low threshold for pain. This might account for lack of significant difference in the daily visual analog scores for pain between groups of patients in these studies. Also, the difference in the results may be due to that they perform both procedures on the same patient which is very difficult for a child to localize the side of pain. There were no episodes of primary or secondary hemorrhage in any patients in our study. This result supported by a study conducted by Pham et al. in 2014, (coblation versus electrocautery tonsillectomy) he found that there were no episodes of primary and secondary bleeding between the two groups. ${ }^{21}$ Tan et al. in 2006, did a study which showed that there were 2 cases of coblation tonsillectomy with secondary hemorrhage that required hemostasis under general anesthesia, both patients made a good and complete recovery. There were no cases of postoperative hemorrhage in the electrocautery tonsillectomy group. This result was not statistically significant. There were no cases of primary hemorrhage. ${ }^{20}$ Regarding healing of tonsillar fossa, in our study when examining the throat at $10^{\text {th }}$ postoperative day (POD), there were no statistically significant difference in healing of tonsillar fossa between the two methods, while at $14^{\text {th }}$ POD, there was a statistically significant difference in which nearly all coblation fossa was healed and slough present in electrocautery fossa (12 out of 30 patients were not fully healed). Temple and Timms did a study, which compares coblation and standard bipolar dissection tonsillectomy showed that, when examining the throat at nine days post-operatively, there was a large difference in the healing of tonsillar fossa, with nearly all the collection fossae fully healed and considerable slough present in the bipolar electrocautery patients. ${ }^{23}$ This might be due to that coblation technology operating at a significantly lower temperature than bipolar 
electrocautery, the surrounding normal pharyngeal tissues exposed to considerably less heat. Thus coblation dissection has advantages over bipolar electrocautery in terms of minimal tissue damage and faster healing in the first two weeks following surgery. Also, this depends on the amount of energy used in bipolar electrocautery in which less energy used will result in faster healing and less pain. The study conducted by Soy et al. in 2014 on bipolar cautery tonsillectomy using different energy doses: pain and bleeding. They found that electrocauterization should be used at lower doses and short-term as possible to decrease the frequency of bleeding episodes, alleviate postoperative pain and accelerate wound healing. ${ }^{24}$ Also, in another study which was conducted by Magdy et al., who did the comparison of coblation with dissection -suture ligation (group A), monopolar electrocautery (group B) and CO2 laser (group C) in adult patients in 2007, in which electrocautery produced statistically significantly slower healing than did coblation. ${ }^{17}$ This result was similar to the result of our study. Hong et al. in 2013 did a study about coblation vs. electrocautery tonsillectomy and showed that there was no significant difference in wound healing between the two groups. ${ }^{25}$ The weakness in our study include relatively small sample size, non-blinded subjects, and investigators, and the pain due to adenoidectomy contribute to postoperative pain. Also, the considerable cost of the coblation wand and difficulty in availability are factors to consider, when compared with bipolar electrocautery which is cheap and available in all surgical theatre.

\section{Conclusion}

Bipolar electrocautery tonsillectomy offers the same operative speed, less intraoperative blood loss, more postoperative pain and delayed healing of tonsillar fossa when compared with coblation tonsillectomy. Because of the small sample size, a larger randomized controlled trial study comparing these two surgical approaches in pediatric patients is recommended. There is a need for the exclusion of adenoidectomy because it contributes to post-operative pain.

\section{Competing interests}

The authors declare that they have no competing interests.

\section{References}

1. Özler GS, Tatar EC. Comparing traditional cold knife tonsillectomy with a new technique plasma knife tonsillectomy. Turk Arch Otolaryngology 2013; 51:114-7.

2. Businco LDR, Tirelli GC. Pediatric tonsillectomy: Radiofrequency-based plasma dissection compared to cold dissection with sutures. (Accessed January 19, 2011 at http://www. businco.it/studio).

3. Shah SA, Ghani R. Evaluation of safety of bipolar diathermy tonsillectomy. J Ayub Med Coll Abbottabad 2007; 19(4):947.

4. Oko MO, Ganly I, Loughran S, Clement WA, Young D, Geddes NK. A prospective randomized single-blind trial comparing ultrasonic scalpel tonsillectomy with tonsillectomy by blunt dissection in a pediatric age group. Otolaryngol Head Neck Surg 2005; 133(4):579-84.

5. Back L, Paloheimo M, Ylikoski J. Traditional tonsillectomy compared with bipolar radiofrequency thermal ablation tonsillectomy in adults. Arch Otolaryngol Head Neck Surg 2001; 127(9):1106-10.

6. Roje Z, Racic G, Dogas Z, PisacVP, Timms M. Postoperative morbidity and histopathologic characteristics of tonsillar tissue following coblation tonsillectomy in children: A prospective randomized single-blind study, Coll Antropol 2009; 33(1):293-8.

7. Mitic S, Tvinnereim M, Lie E, Saltyte BL. A pilot randomized controlled trial of coblation tonsillectomy versus dissection tonsillectomy with bipolar diathermy haemostasis. Clin Otolaryngol 2007; 32:261-7.

8. Philpott CM, Wild DC, Mehta D, Daniel M, Banerjee AR. A double-blinded randomized controlled trial of coblation versus conventional dissection tonsillectomy on postoperative symptoms. Clin Otolaryngol 2005; 30:143-8.

9. Parker D, Howe L, Unsworth V, Hilliam R. A randomised controlled trial to compare postoperative pain in children undergoing tonsillectomy using cold steel dissection with bipolar haemostasis versus coblation technique. Clin Otolaryngol 2009; 34:225-31. 
10. Xuanqian X, Nandini D. Comparison of coblation tonsillectomy and electrocautery tonsillectomy inpediatric patients. Technology Assessment Unit of the McGill University Health Centre 2008; 7(34):47-53.

11. Matin MA. Coblation tonsillectomy versus blunt dissection tonsillectomy. The ORION Medical J 2006; 23:330-1.

12. Belloso A, Chidambaram A, Morar P, Timms MS. Coblation tonsillectomy versus dissection tonsillectomy: Postoperative hemorrhage. Laryngoscope 2003; 113:2010-3.

13. Javed F, Sadri M, Uddin J, Mortimore S, Parker D. A completed audit cycle on post-tonsillectomy haemorrhage rate: Coblation versus standard tonsillectomy. Acta Otolaryngol 2007; 127(3):300 -4 .

14. Shapiro N L, Bhattacharyya N. Cold dissection versus coblation-assisted adenotonsillectomy in children. Laryngoscope 2007; 117:406-10.

15. Isaacson G. Tonsillectomy healing. Ann Otol Rhinol Laryngol 2012; 121(10):645-9.

16. Parsons SPCordes, SR Comer B. Comparison of posttonsillectomy pain using the ultrasonic scalpel, coblator, and electrocautery. Otolaryngol Head Neck Surg 2006; 134:106-13.

17. Magdy EA, Elwany S, El-Daly AS, Abdel-Hadi M, Morshedy MA. Coblation tonsillectomy: A prospective, double-blind, randomized, clinical and histopathological comparison with dissection -ligation, monopolar electrocautery and laser tonsillectomies. J Laryngol Otol 2008; 122:28290.

18. Chang KW. Randomized controlled trial of coblation versus electrocautery tonsillectomy. Otolaryngol Head Neck Surg 2005; 132:273-80.

19. Fawzy AH, Hussien A, Ashour B. Coblation versus bipolar diathermy for adult tonsillectomy. Med.J Cairo Univ 2012; 80(1):491-4.

20. Tan AK, Hsu PP, Eng SP, Nq YH, Lu PK, Tan SM, et al. Coblation vs electrocutery tonsillectomy: Postoperative recovery in adults. Otolaryngol Head Neck Surg 2006; 135(5):699_ 703.

21. Pham V, Rana N. Postoperative outcomes in coblation versus electrocautery tonsillectomies. Int J Otolaryngol Head Neck Surg 2014; 3:32-41.

22. Stoker KE, Don DM. Pediatric total tonsillectomy using coblation compared to conventional electrocautery: A prospective controlled singleblind study. Otolaryngol Head Neck Surg 2004; 130(6):666-75.

23. Temple $\mathrm{RH}$, Timms MS. Paediatriccoblation tonsillectomy. Int J Pediatr Otorhinolaryngol 2001; 6:195-8.

24. Soy FK, Dündar R, Yazici H, Kulduk E, Aslan M, Sakarya EU. Bipolar cautery tonsillectomy using different energy doses: pain and bleeding. Int J Pediatr Otorhinolaryngol 2014; 78(3):402-6.
25. Hong SM, Cho JG. Coblation vs. electrocautery tonsillectony: A prospective randomized study comparing clinical outcomes in adolescents and adults. Clin Exp Otorhinolaryngol 2013; 6(2):90-3. 